\title{
The Importance of the Freeway Space in ENT Evaluations of Airway Interferences
}

\author{
Robert M Mason* \\ Department of Surgery, Emeritus Professor of Surgery, Previous Chief of Orthodontics, Duke University Medical Center, USA
}

*Corresponding author: Robert M Mason, Department of Surgery, Emeritus Professor of Surgery, Previous Chief of Orthodontics, Duke University Medical Center, Durham, NC, USA.
Received Date: July 27, 2020

Published Date: August 10, 2020

\section{Short Communication}

In the normal dental rest position, teeth are not in contact. The small vertical space between upper and lower teeth that normally occurs at rest is referred to as the dental freeway space, or interocclusal space. The normal freeway space measures $2-3 \mathrm{~mm}$ at the molars, and 4-6mm at the incisors [1]. The most common causes of orofacial myofunctional disorders (OMDs) are airway interferences and allergies [2]. An OMD, whether the result of a digit habit or an altered oral posture such as a tongue protruding between the incisors, will hinge the mandible open, thus increasing the vertical rest position, or freeway space between the upper and lower jaws and teeth.

Only a slight vertical increase in the resting freeway space for hours per day is needed to initiate continued and unwanted vertical tooth eruption $[3,4]$. A prime example is a tongue rest position between the incisors that inhibits further eruption of anterior teeth, while the increased posterior vertical dimension results in triggering the posterior teeth to continue erupting. The dental result of this differential dental eruption is an anterior open bite. Conversely, some patients have a clenching habit pattern that involves keeping teeth together for hours per day. Closure of the bite and freeway space for extended periods can lead to dental trauma and dysfunction of the temporomandibular joint apparatus [1]. Altogether, a disruption of the normal resting dental freeway space, either open beyond the normal range, or closed, leads to negative, unwanted consequences in the dentition.

Prior to examination, it is suggested that young patients be asked to blow their nose. This suggestion is based on aerodynamic studies of the airway showing that many children have poor nasal hygiene [5,6]. Nasal debris can increase nasal resistance during quiet respiration by up to $50 \%[5,6]$. An inability to properly manage nasal debris encourages a mouth open posture and mouth breathing. Teaching a patient to monitor and clear nasal debris is an appropriate component of a treatment plan for children with airway interferences.

\section{Clinical Assessment}

Since it is impractical to measure the dental freeway space by direct inspection, a simple extraoral procedure is recommended. This will involve measuring the vertical distance between the base of the nose and the bottom of the chin with a millimeter ruler, under two conditions:

1. with the patient in his/her normal mandibular and dental rest position.

2. with the patient biting down on the back teeth, with dentition in a closed position. The difference in the two measurements will reveal the patient's resting freeway dimension [7].

\section{Recommendation}

A freeway dimension open beyond the normal range should be recorded and shared with the patient or family. This dimension can serve as a comparative measure following ENT management of airway interferences, and when myofunctional therapy is utilized to establish and stabilize a normal vertical rest position of the teeth and jaws.

\section{Acknowledgement}

None. 


\section{Conflict of Interest}

\section{No conflict of interest.}

\section{References}

1. Sicher H, DuBrul EL (1970) Oral Anatomy. (5 ${ }^{\text {th }}$ Edn), CV Mosby, USA.

2. Mason RM, Franklin H (2014) Orofacial Myofunctional Disorders and Otolaryngologists. Otolaryngol (Sunnyvale) 4: e110.

3. Mason R (1988) Orofacial myology: Current trends. International Journal of Orofacial Myology 14(1): 49-55.
4. Proffit WR (1986) Contemporary Orthodontics. CV Mosby, St Louis, USA

5. Riski JE (1983) Airway interference: objective measurement and accountability. International Journal of Orofacial Myology 9: 12-15.

6. Mason RM, Riski JE (1983) Airway interference: a clinical perspective. Int J Orofacial Myology 9: 9-11.

7. Mason RM (2005) A retrospective and prospective view of orofacial myology. Int J Orofacial Myology 31: 5-14. 